\title{
Application of Traditional Water Structures as Passive Energy Systems Case: Shushtar Kats
}

\author{
Mohammadjavad Mahdavinejad $^{1}$, Fahimeh Mirzaei $^{2, *}$, Mohammadhossein Ghasempourabadi ${ }^{3}$ \\ ${ }^{1}$ Faculty of Arts and Architecture, Tarbiat Modares University, Tehran, Iran \\ ${ }^{2}$ Faculty of Architecture, International University of Imam Khomeini, Qazvin, Iran \\ ${ }^{3}$ Faculty of Architecture, Art University, Tehran, Iran \\ *Corresponding Author: newwork.arch@gmail.com
}

Copyright (C) 2013 Horizon Research Publishing All rights reserved.

\begin{abstract}
Regional historic architecture in each country contains many positive aspects that may be suitable for developing patterns for new technologies. Vernacular architecture around the world; considers many methods for creating better living conditions and welfare measures. Although it contains some difficulties in covering information from the past, vernacular architecture is a possible means for achieving sustainable architecture. In Iran, sustainable architecture shows creativity in using natural energy. Among them, specialized structures known as Kats in Dezfol and Shushtar in south-western Iran, have been developed for certain conditions. The purpose of this paper is to estimate the amount of natural air flow created between interior and exterior spaces due to temperature variation by exactly measuring 10 evidence points of interior and exterior air temperatures by an electronic thermometer . The results of the research show that the temperature of Kat in summer is less than the average maximum temperature and the average minimum temperature of outdoor, and the thermal condition of the Kat space during the measurement is lower than the thermal comfort limit which is specified in the ashrae standard. By adding moisture created by the Dez River and moist walls in Kat to the air flow, cool and habitable Kats have been created within traditional homes to reduce fossil fuel usage and to preserve the environment. In this paper, Kats passive energy systems are introduced for cooling of modern homes and urban spaces with sustainable criteria.
\end{abstract}

Keywords Kat, Sustainable Architecture, Passive Energy Systems, Natural Ventilation

\section{Introduction}

The tranquility of Iran in a dry and moderate zone of the world is evidenced in the establishment of cities in sides of mountains, in valleys, and adjacent to rivers and seas to preserve unique natural beauty of the region. Thus, life in these cities related to climatic potentials has been regarded as a natural gift. Development of natural resources in these cities is the main reason for achieving the special structures in such areas. Known as an ancient city, Shushtar is a town in south-western that lies between two branches of the Kârun River. In such areas, appropriate and sustainable usage from existing climatic potentials while respecting the laws of the United Nations Educational, Scientific and Cultural Organization (UNESCO) protect enclosures and historical monuments to aid in achieving sustainable societies and cities. At the city urban scale, there are three original approaches including: the use of natural resources, expert design and technology usage, and social valuation.

According to the International Energy Agency, Renewable energy is derived from the natural processes that are replenished constantly. In its various forms, it derives directly from the sun, or from heat generated deep within the earth. Included in the definition is electricity and heat generated from solar, wind, ocean, hydropower, biomass, geothermal resources, and biofuels and hydrogen derived from renewable resources [1]. Among from all the Renewable Energies, Wind power is growing at the rate of $30 \%$ annually, with a worldwide installed capacity of 158 gig watts (GW) in 2009 and is widely used in Europe, Asia, and the United States [2]. Hence, the international demand for the new innovative methods to utilize the wind power is considerably increasing. Passive coolers are defined as the heat removers from the building and environment using the natural processes of evaporation, radiation, convection and conduction [3]. Using different static cooling systems was one of the most important strategies of the human for being protected from the excessive heat of the environment in the past. Several researches have been conducted to study the performance of these systems and the strategies for improving them and even new ideas for using static cooling systems are given. One of the sources which have high potential for generating the coldness required for the thermal comfort of the human is the direct and indirect use of the underground spaces. In this regard, B.Barker, Michael (1986) performed an extensive research on the energy consumption 
of four important underground buildings of the USA, that in all of the buildings, the energy consumption in the winter and summer was considerably lower than the other buildings that hadn't used the underground spaces [3]. Ojima.Toshio and Gideon (1996) divided the use of underground spaces into five groups, which were used in ten different ways [4].

Dr. Bahadorinejad and Dr. yaqodi (2006) believed that the function of traditional systems is one of the appropriate methods to reduce energy consumption. They analyzed and calculated the amount of natural cooling and natural ventilation that can be used in house by using of winds catcher, sardab, courtyard, basement and etc. as the elements of traditional Iranian houses [5].S.M Jafarian et al. (2009) analyzed the performance of the passive cooling system using the underground canals in the ancient building of the city of Bam, and they concluded that the warm air, by passing the underground canal, become so cold and its humidity increases [6]. Vikas Bansal et al. (2011) analyzed the performance of the underground canals and their combination with water coolers in order to create coldness in hot and dry regions, and it was determined, if we first pass the air into the underground canals and after generating a precooling, pass the air to the water cooler, the output of the water coolers will increase significantly [7]. Dr. Mahdavinejad (2013) researched about the Thermal and Cryogenic Performance of Shevadun in Native (Local) Buildings of Dezful Based on Modeling and Environmental Measuringch. The research results show that the temperature of the shevaduns in summer is less than the average maximum and the average minimum temperature of the outdoors, The effect of the cool air in shevadun on the summer place above it which are connected to each other by a trapdoor, is very important, and the field data show that if the summer place is connected to the shevadun, the its average temperature is about $4\left({ }^{\circ} \mathrm{C}\right)$ lower than when the connecting trapdoor is closed. And when the trapdoor is open, the relative humidity of the summer place will be about 2 to 3 percent higher [8]. Also, he (2013) analyzed the functional system of the Kats as a concept in Design of Green Sidewalk [9].

All of the conducted researches show the high potential of the underground spaces and the thermal mass of the soil for achieving thermal comfort and reducing the energy consumption. But the point that distinguishes this research, is studying the performance of one of the most traditional methods of using the thermal mass of the soil by field sampling. The main goal of this study is to measure the variance in temperature inside and outside of Kats to determine the amount of air_flow created between the two spaces and examine their roles in green design in Shushtar.

\section{Materials and Methods}

The research in this study is approached experimentally and quasi-experimentally. Techniques are related to climatic potentials and green design. Information was collected through library research methods and physical studies. [10] In this paper we attempt to determine the most important climatic potentials that can be used in green design in Shushtar. Moreover, we determine the amount of variance in temperature between the areas inside and outside of Kats and examine methods for taking advantage of such temperature variance in rearrangement plans.

To realize these objectives, we measure maximum and minimum temperatures at ten main points with an electronic thermometer to determine average temperature, and we consider the principle in which the temperature variation creates air_flow.

\subsection{Shushtar and Kat Function}

Shushtar is a perfect example of interaction between man and nature, and the Kârun River is one of the great rivers of Iran. Figure 1 shows its origin from the Zagros Mountain straits through Khuzestan Province to the Shushtar plain.

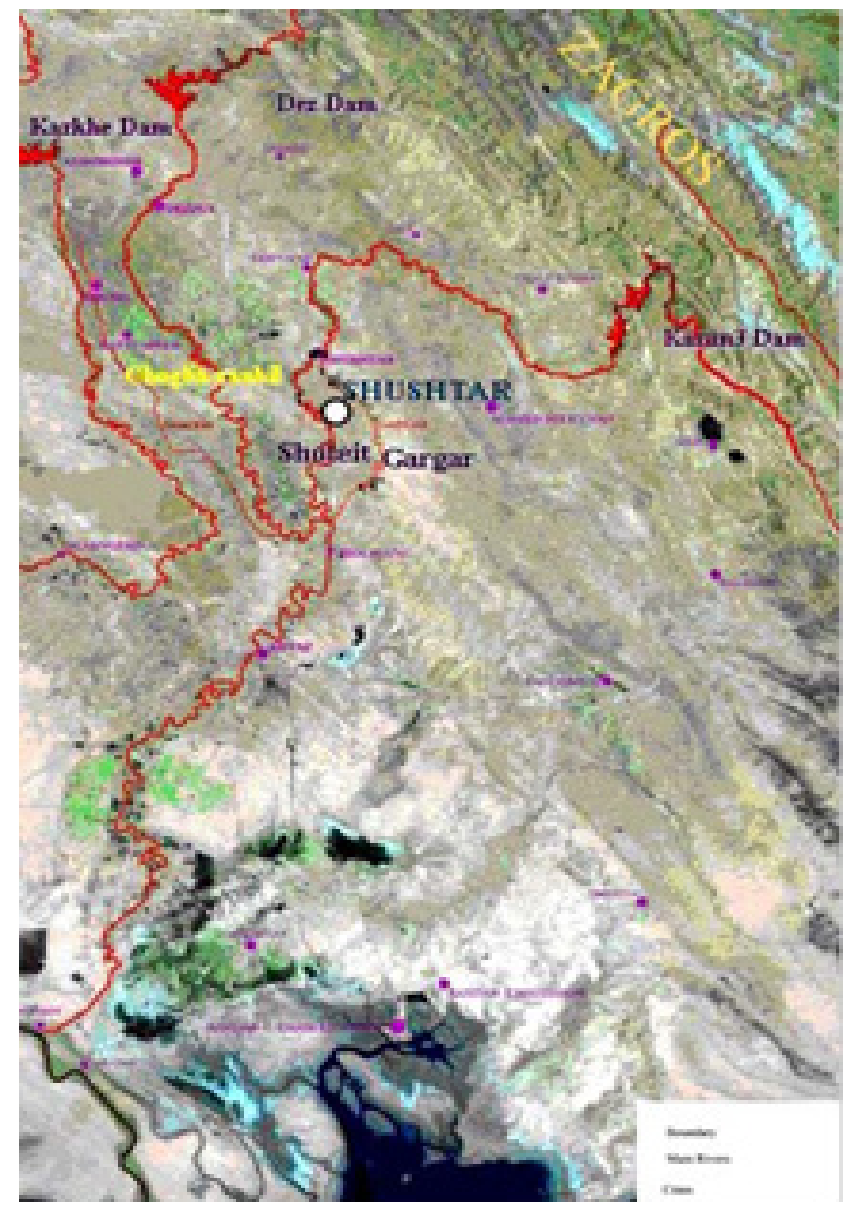

Figure 1. General landscape of Shushtar historical hydraulic system. [11]

In cities such as Dezful and Shushtar underground spaces known as Shavaduns use the river to chill building spaces. The Shavaduns shown in Figures 2 and 4 were constructed $5-12$ beneath the building and are accessed by stairs. Figures 3,5 , and 6 show that most of these structures are connected underground. [11] 


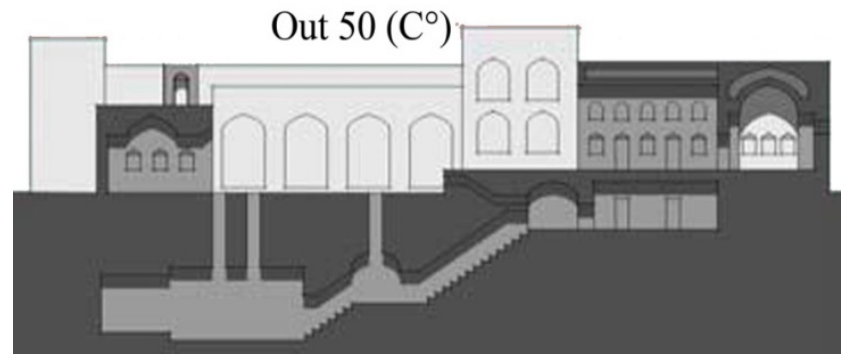

Figure 2. Shavadun structure. [11]

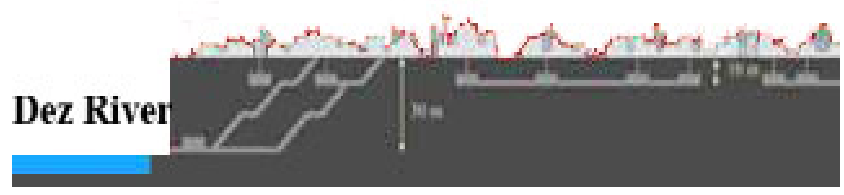

Figure 3. Connection between Shavaduns underground. [11]

The warm and semi-humid climate of Shushtar, which neighbors the Dez River, and the access to cool water and high land favor the formations of Kats. Thus, city architect were able to use the river's cool water and moderate climate to provide favorable living conditions in temperatures higher than $50\left({ }^{\circ} \mathrm{C}\right)$, even before the invention of the electric cooling equipment. [11]

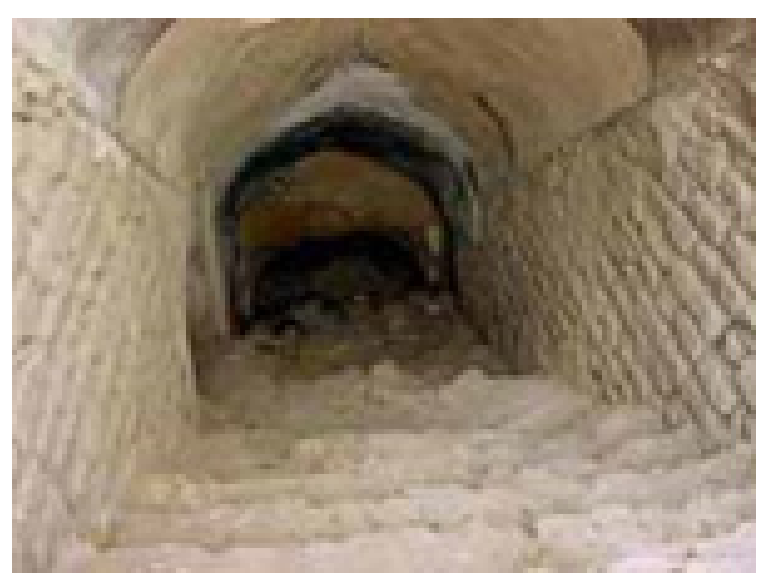

Figure 4. Kat structure. [11]

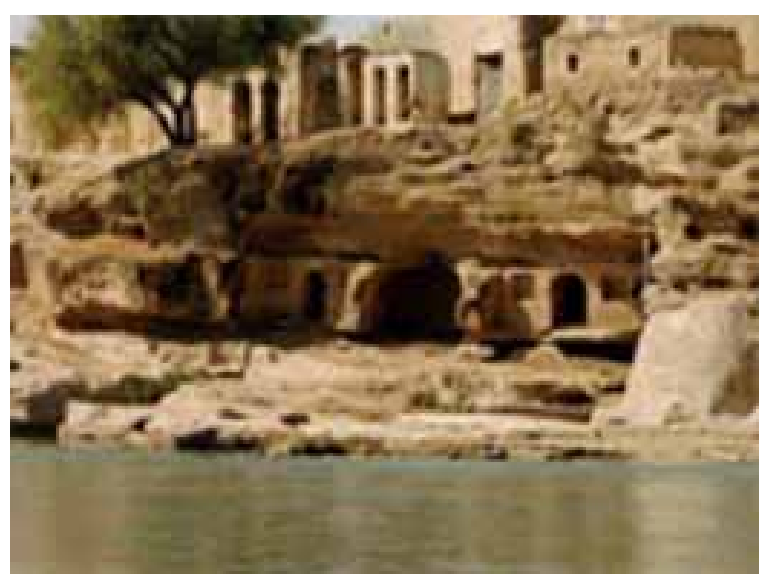

Figure 5. Stairway access to Kat. [12]

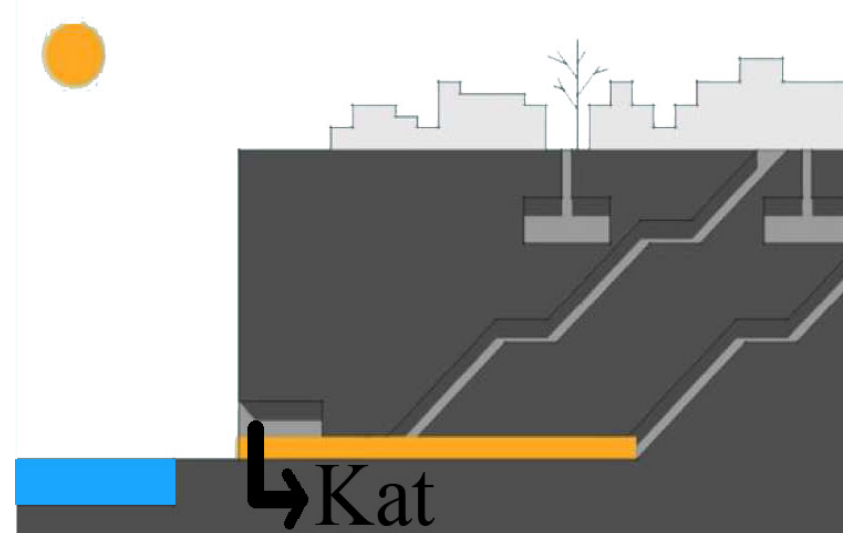

Figure 6. The Kat. [12]

Kat spaces are lower than the surrounding temperature by approximately $10\left({ }^{\circ} \mathrm{C}\right)$. The wind blowing over the river cools and creates circulation in these structures. [13] Table 1 shows that the temperatures in three building are lower and the humidity is higher than values measured outside, which illustrates the roles of Kats in providing improved living conditions.

Table 1. Differences in temperature and humidity inside and outside of Kats. [9]

\begin{tabular}{|c|c|c|c|}
\hline $\begin{array}{c}\text { Parameters affecting the } \\
\text { comfort conditions }\end{array}$ & $\begin{array}{c}\text { Buildin } \\
\text { g } 1\end{array}$ & $\begin{array}{c}\text { Building } \\
2\end{array}$ & $\begin{array}{c}\text { Buildin } \\
\mathrm{g} \mathrm{3}\end{array}$ \\
\hline $\begin{array}{c}\text { Temperature drop of outside } \\
\text { temperature }\left(40\left({ }^{\circ} \mathrm{C}\right)\right)\end{array}$ & 29.3 & 30.8 & 32.2 \\
\hline Increase of moisture $($ Outside $17 \%)$ & $36.7 \%$ & $34.15 \%$ & $32.9 \%$ \\
\hline
\end{tabular}

As shown in Figure 7, Kats are also used as wind-catchers. The hot air after blowing over the river is cooled by the cold river water. Figure 8 shows the process by which the hot air blows over the Dez River and is cooled upon entrance to Kats and Shavaduns.

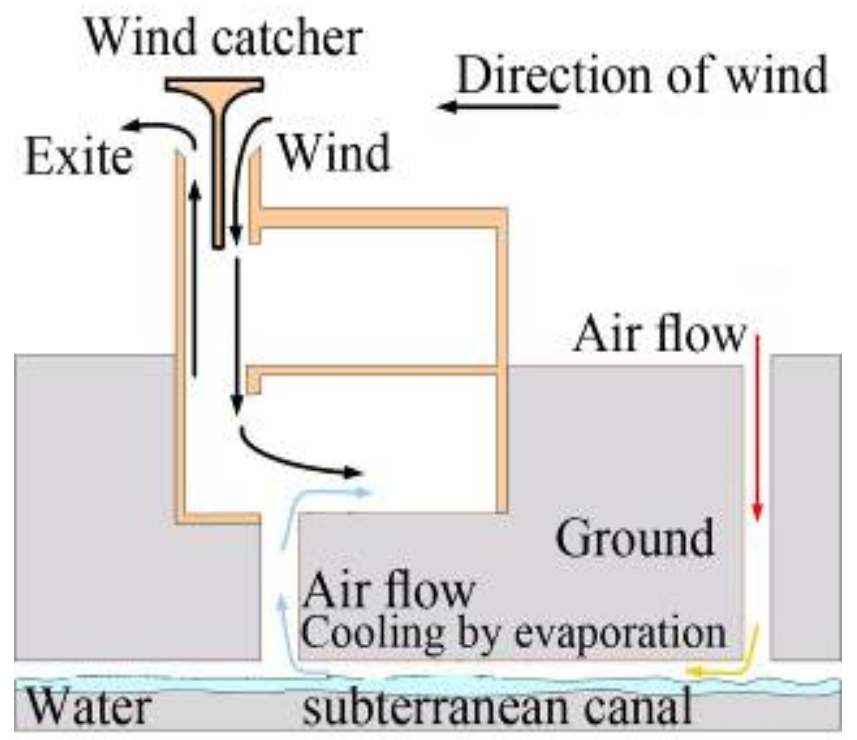

Figure 7. wind-catcher. [15] 


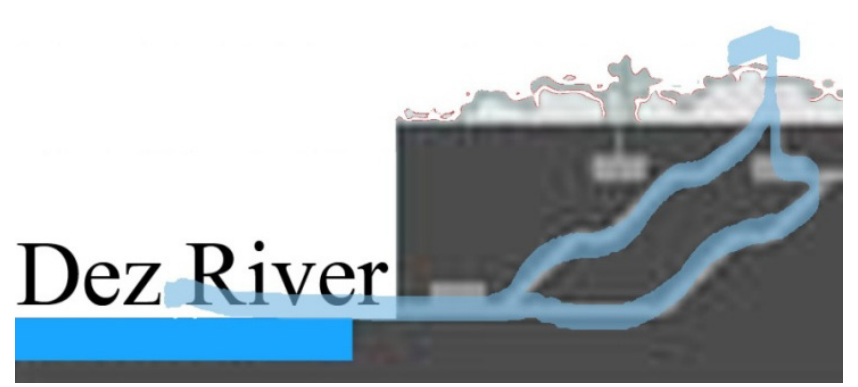

Figure 8. Air circulation process in Kats. [11]

\section{Results and Discussion}

\subsection{Case Studies}

Because of its high altitude, lower groundwater levels, and soil characteristics, homes in Shushtar are constructed with Shavaduns, many of which are connected under-ground. In this manner, a network is formed to connect the neighboring houses to the Dez River. [11]

In the following section, examples are given to show the effects of Shavaduns and Kats on temperature reduction, and the subsequent section discusses the role of Kats separately.

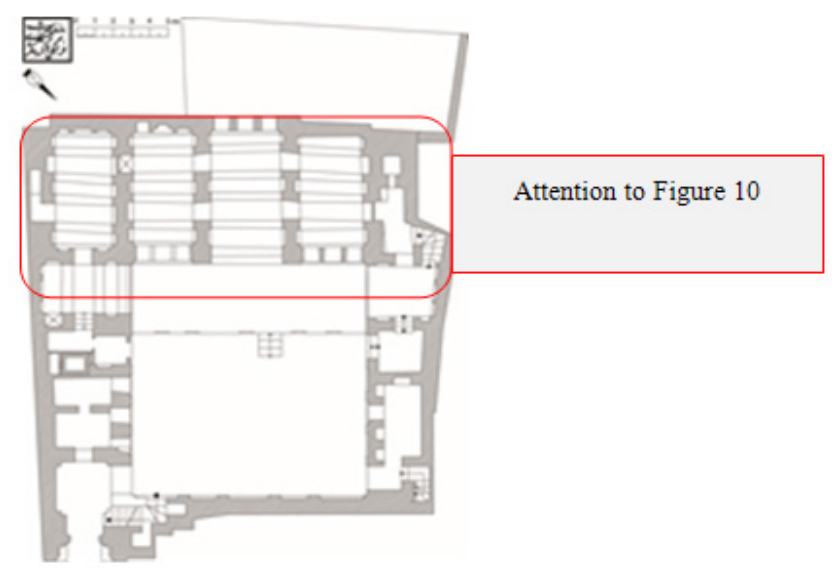

Figure 9. Ground floor of Aminzadeh home plan in Shushtar. [14]

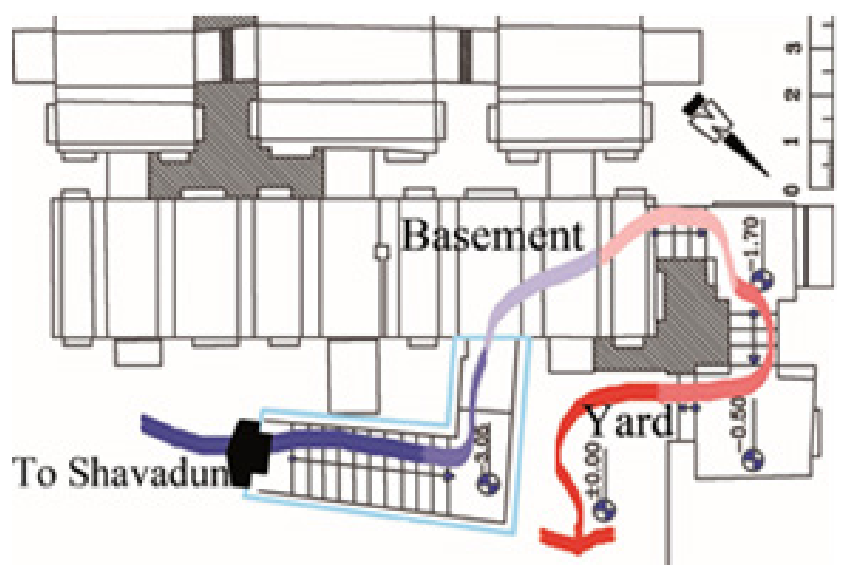

Figure 10. Basement showing the flow of cold air from the Kats to the yard. [Designed by Authors] [6]

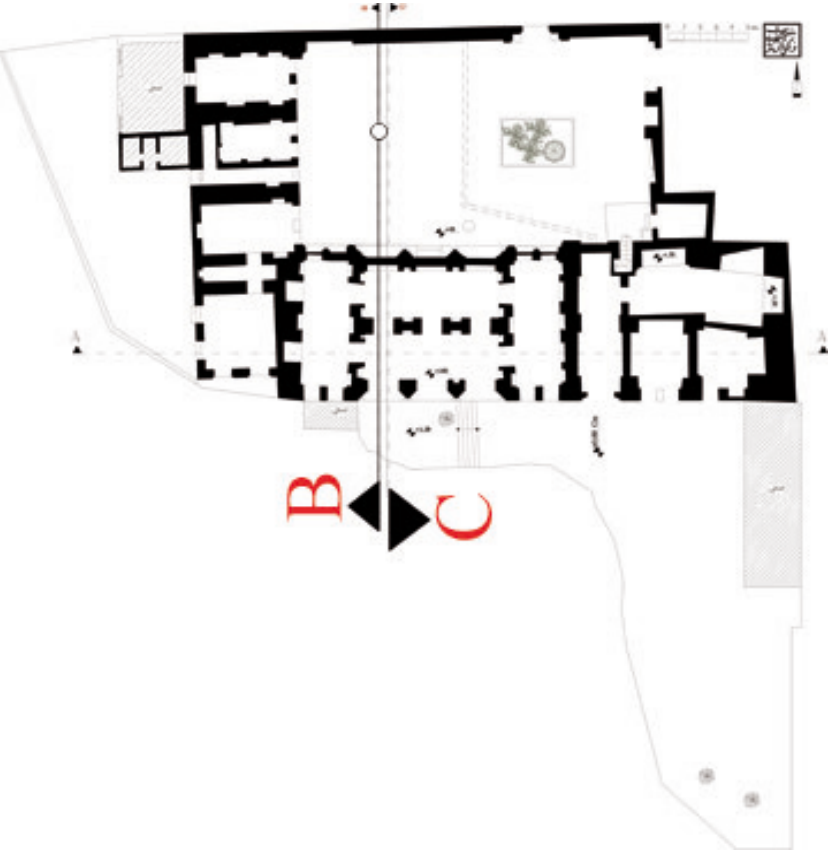

Figure 11. Ground floor of Marashi home plan in Shushtar [14]

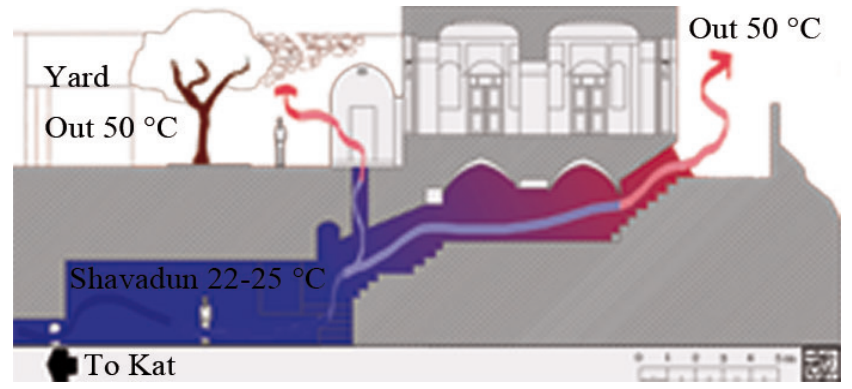

Figure 12. Section C-C: Air_flow from Shavadun to home and yard. [Designed by Authors] [14]

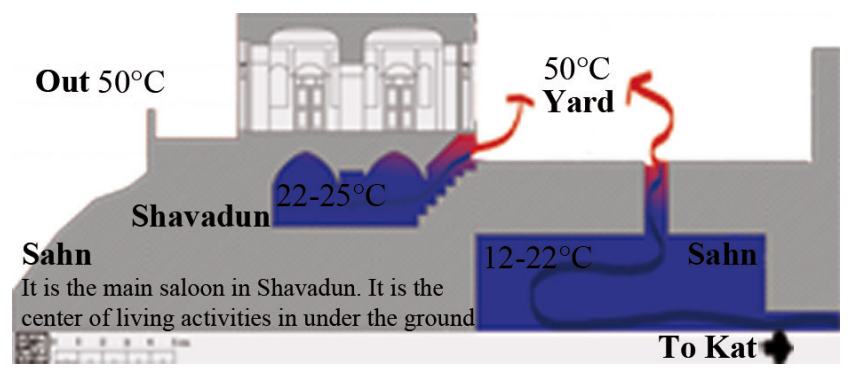

Figure 13. Section B-B: Air flow from Shavadun and Sahn to home and yard. [Designed by Authors] [14]

\subsection{Effects of Kats}

The temperature of the earth crust at the down parts is about $800\left({ }^{\circ} \mathrm{C}\right)$, and for each $100(\mathrm{~m})$ increase of the height, the temperature decreases $3\left({ }^{\circ} \mathrm{C}\right)[5]$ and this temperature decrease continues until the temperature of the earth outer crust reaches the ambient temperature, this part of the crust is the part that we live on. The down surface of this crust that the underground stores of the building are built inside it, is less affected from the ambient temperature, so that the daily 
temperature change which is $17\left({ }^{\circ} \mathrm{C}\right)$ only affects $1\left({ }^{\circ} \mathrm{C}\right)$ on the temperature of $1(\mathrm{~m})$ underground and at the depth of 5.6 $(\mathrm{m})$, the temperature change doesn't affect the earth crust [16]. So, we can store the coldness of the winter and the warmness of the summer for 6 months, and because of the high thermal capacity of the soil, the coldness of the winter reaches the earth with a 6 month delay which is the summer season and that is when the inhabitants need this coldness for providing the thermal comfort [17]. The walls of the underground spaces that Kats are one of them, have the temperature equal to the average annual temperature, and according to the statistics of the meteorology organization, this average is $25\left({ }^{\circ} \mathrm{C}\right)$ for Dezful.

In addition to the earth temperature that makes the Kats cold in summer, the ventilation of the Kats air is very important in increasing the coldness of the air. If we ventilate the air of the Kats with a colder and warmer air relative to its natural air, the temperature will change and its walls will lose its heat. So, to decrease the temperature of Kats, some holes are placed for entering and exiting air to decrease the temperature of the Kat walls that it is the opening of Kat toward the Dez River.

Some houses in shushtar city that take place near the Dez River, shavaduns connect to the outdoor toward Dez River by Kats. As a previous research mentioned, there are differences in temperature and humidity, inside of shavadun and Kat with outdoor [8]. It is evident that the recording time is the hottest month of the year in Dezful (in Mordad). The results of the environmental measurements and monitoring show in the figure 14 and 15.

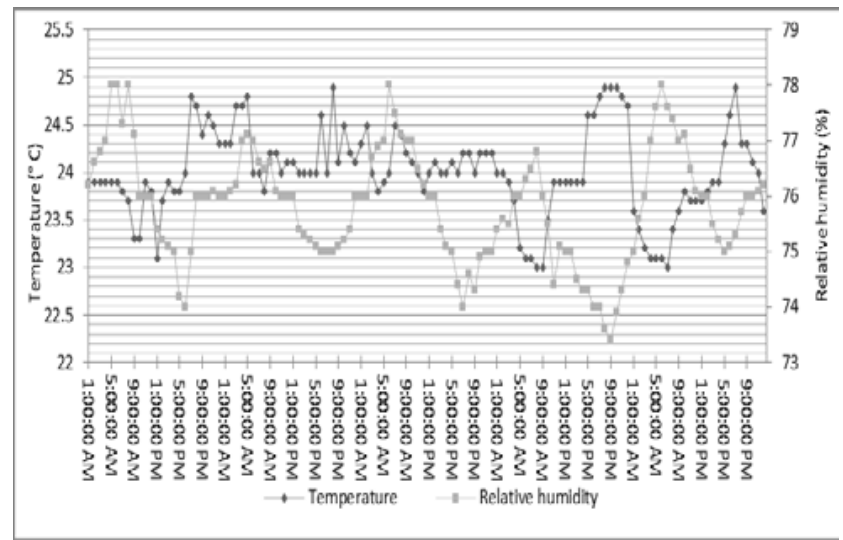

Figure 14. The results of the environmental measurement of the air condition in Shevadun. [8]

It is evident, the air humidity fluctuations of the shevadun is lower than the outdoor air, because it should be protected from the thermal changes of outdoor and should have connections with the humid walls of the space. As it is evident from the figure 14, the maximum temperature of shevadun is $24.9\left({ }^{\circ} \mathrm{C}\right)$ and it occurred at 18 P.M, and the minimum temperature of shevadun in these 5 days is $23\left({ }^{\circ} \mathrm{C}\right)$ and it occurred at 8 A.M. The temperature in shevadun has little fluctuations; we can say that the temperature of shevadun in the summer of Dezful is equivalent to the temperature of winter in this city, because the high thermal mass of the soil reaches the depth of the ground and shevadun with some months delay. The average maximum temperature of the outdoor air is in the interval of 15 to 16 P.M , and it is $48\left({ }^{\circ} \mathrm{C}\right)$, and in the same interval, the average temperature of shevadun is $24.1\left({ }^{\circ} \mathrm{C}\right)$, the significant temperature difference in the hottest hours of day in summer between the temperature inside the shevadun and the temperature of the outdoors, shows the high potential of this space for using its coldness in the buildings spaces and even using it for the times of the day. The average minimum temperature of the outdoors occurs in the interval of 3 A.M to 4 A.M and its value is $28\left({ }^{\circ} \mathrm{C}\right)$, and the average temperature of shevadun in this interval is $23.2\left({ }^{\circ} \mathrm{C}\right)$, which shows that the average minimum temperature in Dezful is higher than the average temperature in that interval in shevadun.

In this study we researched into Kats and measured the maximum and minimum temperatures at 10 points to show average temperatures, and we considered the manner in which temperature variation creates air flow. These 10 examples were randomly selected from various parts of Kats and were measured by an electronic thermometer. The results are shown in Figure 15.

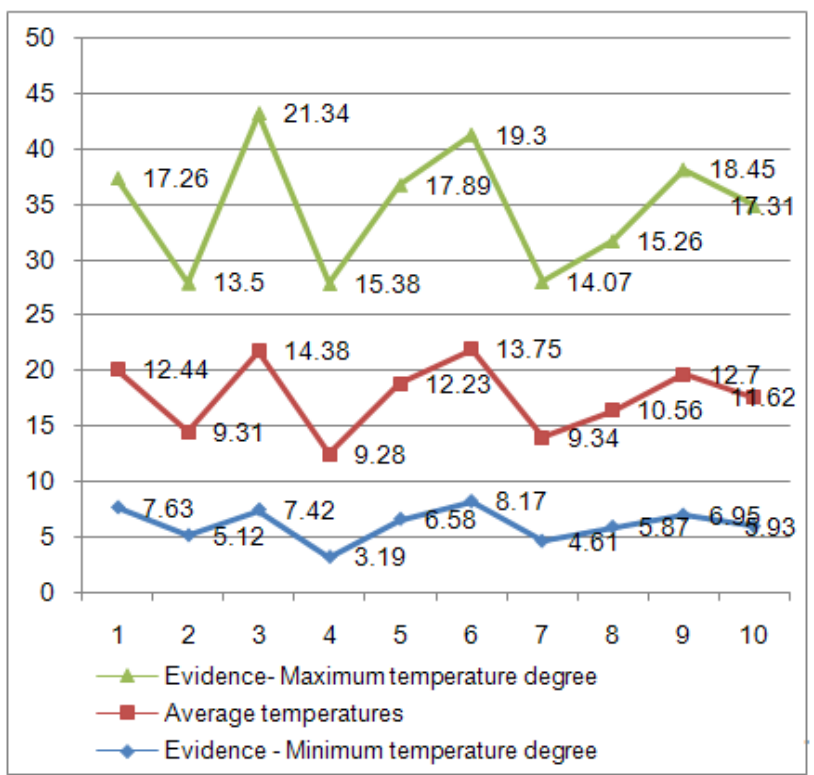

Figure 15. Maximum and minimum temperatures of 10 selected examples. [Designed by authors.]

Figure 15 shows that the average maximum temperature of the Kat is $16.98\left({ }^{\circ} \mathrm{C}\right)$ that it is lower than the temperature of outdoor and lower than the amount of temperature in the human comfort zone. The average minimum temperature of the Kat is $6.15\left({ }^{\circ} \mathrm{C}\right)$ and the total average for minimum and maximum is $12.63\left({ }^{\circ} \mathrm{C}\right)$. The function of Kat is similarity with shavadun. Considering that the temperature variation between the average temperature and the outside air temperature is $37.37\left({ }^{\circ} \mathrm{C}\right)$, natural air_flow occurs between areas of higher air pressure to those of lower air pressure. According to the figure 16-17, the air flows into Kats 
because the average Kat temperature is approximately 12.63 $\left({ }^{\circ} \mathrm{C}\right)$ and the outside air temperature is approximately $50\left({ }^{\circ} \mathrm{C}\right)$. The height difference between the two points is approximately $30(\mathrm{~m})$. These factors enable easier air flow at an average speed of approximately $5(\mathrm{~m} / \mathrm{s})$. Therefore, Kats improve human lifestyles with cooling in warm seasons. These details are shown in Figures 15 and 16.
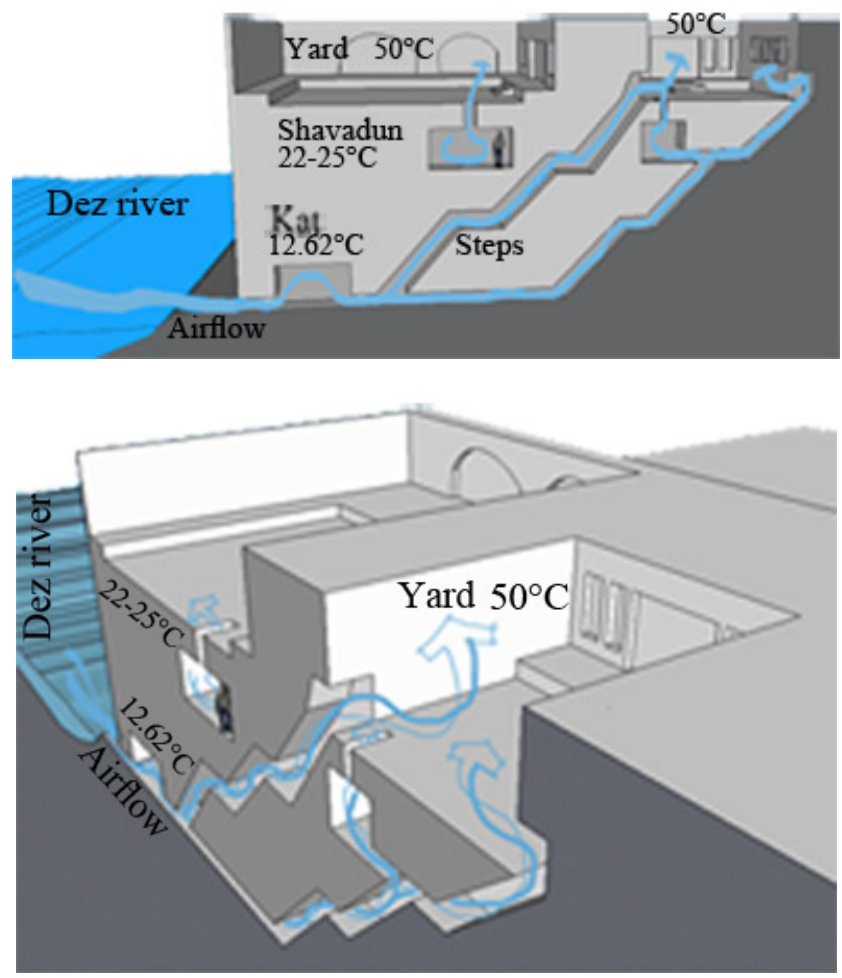

Figure 16-17. Relationship between temperature and air circulation. [Structures designed by authors.]

This research shows the high potential of using the cool air in the underground even without using any mechanical devices for the air expulsion. The average wind speed in Mordad in Dezful at 3 P.M is $2.7(\mathrm{~m} / \mathrm{s})$ in the direction of south west [8], also, the average air_flow in Kat is $5(\mathrm{~m} / \mathrm{s})$ that effect on the air_flow in shavadun. Shavadun with some holes connect to the summer space of house.

The summer place space (the space of house that used in summer) has received the cool air from the shevadun, and because of the high thermal capacity of its walls, keeps this coldness during the day in itself, but after sometime, its temperature is affected by the warm air of outdoors, so that its $29\left({ }^{\circ} \mathrm{C}\right)$ at 3 A.M reaches the temperature of about 34 to $35\left({ }^{\circ} \mathrm{C}\right)$ at 3 P.M $[8]$.

The performance of Kat depends on two factors: 1- the underground temperature in depth 2 - the ventilation of the air inside Kat.

\section{Conclusions}

Many natural resources of energy cater to the needs of modern humans. A complete understanding of these natural resources enables accurate analysis and wise usage, which helps to reduce the use of fossil fuels and enables adaptation to the principles of green architecture. Our ancestors have benefited by using the Dez River and soil strength in Shushtar as virtual potentials for creating special spaces known as Shavaduns, Kats, and underground passageways. These spaces have proper temperature and appropriate dimensions and scale for accommodating one or more families. Kats act as passive energy systems by using natural air flow created by inside and outside air temperature variation. This natural air flow is chilled and freshened by the Dez River.

In modern architecture, however, few Kats are used for this function. However, this study sought the performance, effect and identifying the potentials of one of the native spaces of the Dezful houses for the passive cooling that it may lead to the creation of new plans to develop cool spaces in urban regions of Shushtar, to lower energy consumption in this hot and dry climate. Additional research is necessary to realize this goal. There are some strategies for the preserve and the scientific development of this type of spaces:

- Security in underground spaces should be revived. Because the lack of social security has caused the people do not use it and remove it from their houses.

- By considering the low velocity of the air movement inside the kats and shavaduns, there is a potential that by using the mechanical devices such as fans, users can use the cool air of kats and shavaduns in the upper rooms more efficiently.

- Today, most of the residential spaces have several stores, according to the high potential of the underground for the passive cooling of the spaces, the effective study and design for using the cool air underground in multi-story buildings for reducing the energy consumption in these types of buildings is very important.

\section{REFERENCES}

[1] IEA Renewable Energy Working Party, Renewable Energy into the mainstream, p. 9, 2002.

[2] J. Russell. Record Growth in Photovoltaic Capacity and Momentum Builds for Concentrating Solar Power Vital Signs, June 2010.

[3] S. Alvares, E. Rodriguez, J. L. Molina, The Avenue of Europe at Expo 92: application of cool towers .In : Alvarez, Lopez de Asian, J., Yannas, S., De Oliviera Fernandes, E.(Eds), Architecture and urban space: 9th PLEA International conference, Seville, Spain, 24-27 September 1991.

[4] E. Erell, D. Pearlmutter, Y. Etzion, A multi-stage down-draft evaporative cool tower for semi -enclosed space: aerodynamic performance, Solar Energy, Volume 82, pp. 420-429, 2008.

[5] M. Bahaduri Nejad, M. Yaqubi. Natural ventilation and 
Natural cooling in Iranian traditional buildings, Center for Academic Publication, Tehran, 2006.

[6] D. Pearlmutter, E. Erell, Y. Etzion, I.A. Meir, H. Di, Refining the use of evaporative in an experimental down -draft cool tower, Energy and Building, Volume 23,pp. 191-197, 1996.

[7] V. Bansal, R. Misra, G. Das Agrawal, Performance analysis of earth-pipe-air heat exchanger for summer cooling, Energy and Buildings, Volume 42, Issue 5, pp. 645-648, 2010.

[8] M. Mahdavinejad, N. Nasrollahei, M. Hadiyanpour, Studying the Thermal and Cryogenic Performance of Shevadun in Native (Local) Buildings of Dezful Based on Modeling and Environmental Measuring, American Journal of Energy Research, Vol. 1, No. 3, pp. 45-53, 2013.

[9] M. Mahdavinejad, A. Ghaedi, M. Ghasempourabadi, H. Ghaedi, The Role of Vernacular Architecture in Design of Green Sidewalk (Case Study: Iran, Shushtar), Applied Mechanics and Materials, Vols. 260-261, pp. 65-68, 2013.
[10] L. Groat, D. Wang. Architectural Research Methods, John Wily \& sons, Canada, PP. 275-300, 2002.

[11] M. M. Safaee, Shavadun; Sustainable Architecture in Dezful, pp. $3,6,7,8$.

[12] Online Available: http://whc.unesco.org/en/list/1315

[13] M. Mazidi, M. Mazidi. Numerical analysis of passive cooling systems in hot and dry, Iranian Journal of Energy, No. 28, September 2007.

[14] Online Available: http://shushtarchtb.ir/

[15] Online Available: http://fa.wikipedia.org/wiki/

[16] Solaini G, Dall'O' G, Scansani S. Simultaneous application of different natural cooling technologies to an experimental building. Renewable Energy, 15, pp. 277-82, 1998.

[17] B. Givoni, Semi-empirical model of a building with a passive evaporative cool tower, Solar Energy, 50, pp. 425-434, 1993. 